\title{
Pendugaan Emisi Metana pada Sistem Pengelolaan Tanaman Padi di Kabupaten Minahasa \\ (The Estimation of Methane Emission in The Rice Management System in Minahasa Rregency)
}

\author{
Susan Marlein Mambu ${ }^{1)^{*}}$ \\ 1) Jurusan Biologi, FMIPA Universitas Sam Ratulangi, Manado, Indonesia \\ ${ }^{*}$ E-mail korespondensi: susan_mambu@yahoo.com
}

Diterima 19 Januari 2012, diterima untuk dipublikasikan 31 Januari 2012

\begin{abstract}
Abstrak
Pemanasan bumi secara global karena emisi gas rumah kaca ke atmosfir yang disebabkan oleh kegiatan manusia, cenderung mengalami peningkatan dari waktu ke waktu. Pertanian padi sawah, khususnya sawah teririgasi juga merupakan penyumbang terbesar gas metana ke atmosfer. Oleh karena itu, perlu adanya upaya pengurangan emisi $\mathrm{CH}_{4}$ dari kegiatan budidaya tanaman padi sawah. Penelitian dilakukan untuk mengetahui emisi $\mathrm{CH}_{4}$ dari budidaya padi sawah di kabupaten Minahasa, dengan melakukan estimasi emisi $\mathrm{CH}_{4}$ menggunakan model perhitungan formula untuk estimasi emisi $\mathrm{CH}_{4}$ pada padi sawah. Hasil penelitian ini memberikan informasi keberadaan $\mathrm{CH}_{4}$ dan jumlah produksi emisi $\mathrm{CH}_{4}$ dari lahan padi sawah di Kabupaten Minahasa, yang cenderung mengalami peningkatan dari tahun ke tahun (data tahun 2002 - 2010). Peningkatan emisi $\mathrm{CH}_{4}$ dari lahan padi sawah di Kabupaten Minahasa disebabkan oleh beberapa faktor yaitu luas panen, jenis tanah, jenis varietas, jenis pengairan dan kegiatan budidaya lainnya seperti pemupukan dan pemberian bahan organik (jerami).

Kata kunci: emisi metana, padi sawah
\end{abstract}

\begin{abstract}
Global warming from greenhouse gas emissions to the atmosphere that is caused by human activities tends to be increased over time. Fields of wetland rice, particularly irrigated rice, are also the largest contributor to methane gas to the atmosphere. Therefore, $\mathrm{CH}_{4}$ emissions should be reduced from paddy rice cultivation. This research aimed to measure the production of $\mathrm{CH}_{4}$ emission in the wetland rice fields of Minahasa, using a model calculation formula to estimate $\mathrm{CH}_{4}$ emissions in the rice fields. The results informed the existence and the amount of $\mathrm{CH}_{4}$ production resulted from wetland rice fields in Minahasa, which tended to be increased from year to year (data of year 2002 to 2010). The increment of $\mathrm{CH}_{4}$ emission from wetland rice fields in Minahasa was caused by several factors, i.e. the harvested area, soil types, types of variety, types of irrigation and other cultivation activities such as fertilization and providing organic material (straw).

Keywords: methane emission, wetland rice
\end{abstract}

\section{PENDAHULUAN}

Selain gas $\mathrm{CO}_{2}$, gas metana $\left(\mathrm{CH}_{4}\right)$ merupakan gas yang sangat penting dalam hubungannya sebagai gas rumah kaca. Gas ini mampu memerangkap panas 21 kali lebih kuat dibandingkan dengan gas $\mathrm{CO}_{2}$ atau memiliki potensi pemanasan global 21 
kali lebih besar daripada gas $\mathrm{CO}_{2}$ (Anonimous 2007a).

$\mathrm{CH}_{4}$ juga mempunyai daya serap radiasi setiap kenaikan $1 \mathrm{ppm}$ 32 kali lipat daripada $\mathrm{CO}_{2}$, maka dalam jangka panjang pengaruh $\mathrm{CH}_{4}$ akan makin penting(Bouwman et al. 1990).

Pertanian padi sawah, khususnya sawah teririgasi juga merupakan penyumbang terbesar gas metana ke atmosfer. Secara global diperkirakan sekitar 18 sampai $280 \mathrm{Gt} \mathrm{CH}_{4}$ per tahun dilepas ke atmosfer oleh pertanian padi sawah. Kondisi lahan sawah yang tergenang menyebabkan kondisi lingkungan yang sangat baik bagi terbentuknya $\mathrm{CH}_{4}$ (Lindau et al. 1990).

Pola penggenangan terus menerus pada budidaya padi sawah membutuhkan air dalam jumlah yang besar. Selain sebagai suatu pemborosan pemakaian sumber daya air, penggenangan menyebabkan $\mathrm{pH}$ tanah mendekati netral, sehingga dekomposisi bahan organik dapat berlangsung dan menyebabkan terbentuknya gas $\mathrm{CH} 4$ (Suparyono et al. 1994).

Setyanto (1997) penggunaan pupuk anorganik seperti $\left(\mathrm{NH}_{4}\right)_{2} \mathrm{SO}_{4}$ dan urea secara intensif dan penemuan varietas - varietas padi berumur genjah telah merangsang tingkat kenaikan produksi padi, karena bisa menambah periode tanam, tetapi penggunaan pupuk tersebut ternyata berperan besar dalam pembentukan $\mathrm{CH}_{4}$ dari lahan sawah. Padi merupakan tanaman kultur terpenting yang dipunyai umat manusia, karena padi merupakan makanan pokok bagi hampir separuh dari populasi dunia (Steenis 1981). Perakaran beberapa varietas padi seringkali melepas eksudat berupa senyawa organik ke sekitarnya. Senyawa ini dalam tanah memberikan energi dan substrat bagi mikroorganisme tanah di sekitar perakaran, seperti bakteri penambat $\mathrm{N}$, pelarut $\mathrm{P}$, dan juga terhadap bakteri metanogenik pelepas gas $\mathrm{CH}_{4}$ (Makarim dan Suhartatik 2006).

Penggenangan diam di sawah merupakan lingkungan yang cocok untuk pembentukan $\mathrm{CH}_{4}$ terutama di daerah tropis, karena penggenangan diam akan meningkatkan suhu tanah dan suhu air di lahan sawah pada siang hari dengan kisaran $30^{\circ} \mathrm{C}$ $40^{\circ} \mathrm{C}$. Sebagian besar bakteri metanogenik yang berperan dalam proses pembentukan $\mathrm{CH}_{4}$ sangat aktif pada suhu optimum $30^{\circ} \mathrm{C}-40^{\circ} \mathrm{C}$ (Notohadiprawiro 1992).

Penggunaan pupuk anorganik (urea) secara intensif untuk merangsang kenaikan produksi padi, berperan besar juga terhadap kenaikan emisi $\mathrm{CH}_{4}$ dari lahan sawah. Pupuk urea dengan rumus kimia ( $\mathrm{CO}$ $\left.\left(\mathrm{NH}_{2}\right)_{2}\right)$ atau $\mathrm{NH}_{2} \mathrm{CO} \mathrm{NH}_{2}$ merupakan pupuk kimia yang mengandung $\mathrm{N}$ berkadar tinggi dan zat hara yang sangat diperlukan tanaman (Palimbani 2007).

$\mathrm{H}_{2}, \mathrm{CO}_{2}$ dan asetat di dalam urea akan digunakan untuk pertumbuhan bakteri metanogenik dan selanjutnya Urea akan mengalami hidrolisis atau penguraian oleh bakteri metanogenik menghasilkan $\mathrm{CH}_{4}$ dan $\mathrm{CO}_{2}$. Pemberian bahan organik tanpa melalui proses lanjutan (kompos) juga meningkatkan produksi $\mathrm{CH}_{4}$ (Wassman et al. 1993).

Organisme perombak bahan organik memegang peranan penting, karena sisa organik yang telah mati diuraikan menjadi unsur - unsur yang dikembalikan ke dalam tanah (N, P, K, $\mathrm{Ca}, \quad \mathrm{Mg}$ dan lain - lain) dan dipancarkan ke atmosfir dalam bentuk gas $\mathrm{CH}_{4}$ atau $\mathrm{CO}_{2}$, sehingga siklus hara berjalan secara alami dan proses kehidupan di muka bumi dapat berlangsung.

Menurut Setyanto (1997), tanaman padi memegang peranan penting dalam emisi gas $\mathrm{CH}_{4}$ dari lahan sawah. Diduga $\mathrm{CH}_{4}$ yang dilepas dari lahan sawah ke atmosfir dipancarkan melalui tanaman, dan sisanya melalui gelembung air 
(ebullition). Ruang udara pada jaringan aerenkim daun, batang dan akar yang berkembang dengan baik, menyebabkan pertukaran gas pada tanah tergenang berlangsung cepat. Pembuluh tersebut bertindak sebagai cerobong bagi pelepasan $\mathrm{CH}_{4}$ ke atmosfir.

Mekanisme emisi $\mathrm{CH}_{4}$ melalui aerenkim terjadi akibat perbedaan gradient konsentrasi air di sekitar akar dan ruang antar sel lisigenus pada akar, sehingga $\mathrm{CH}_{4}$ terlarut di sekitar perakaran berdifusi ke permukaan cairan akar menuju dinding sel korteks akar. Di dalam dinding korteks akar, $\mathrm{CH}_{4}$ terlarut akan berubah menjadi gas dan disalurkan ke batang melalui jaringan aerenkim dan ruang antar sel lisigenus. Selanjutnya $\mathrm{CH}_{4}$ akan dilepaskan melalui pori - pori mikro pada pelepah daun bagian bawah (Wagatsuma et al. 1990).

Menurut Setyanto dan Abubakar (2006), masih terdapat faktor-faktor yang memegang peranan penting dalam produksi emisi $\mathrm{CH}_{4}$ dari lahan sawah antara lain pembibitan, pengolahan tanah, pemupukan, panen dan pasca panen, sehingga diperlukan penelitian lebih lanjut. Perlu juga diperhatikan, setiap wilayah memiliki karateristik pengelolaan tanaman padi, sehingga memungkinkan terjadinya perbedaan faktor-faktor produksi emisi metana pada masing - masing wilayah.

Selain sebagai salah satu sektor yang menyebabkan dampak perubahan iklim karena menyumbang emisi metana, sektor pertanian juga terkena dampak dari perubahan iklim tersebut. Salah satu dampak besar yaitu perubahan siklus musim kemarau dan penghujan, dan perubahan curah hujan. Kedua perubahan ini akan menimbulkan potensi tingginya kegagalan panen, selain itu petani akan kesulitan untuk menentukan waktu memulai bercocok tanam karena ketidakpastian musim kemarau dan musim hujan.

Budidaya padi sawah yang diterapkan di Minahasa, umumnya sawah dengan irigasi semiteknis dan sederhana, serta juga terdapat sawah tadah hujan. Tanaman pangan yang diusahakan oleh penduduk adalah padi, jagung, ubi-ubian, dan tanaman hortikultura lainnya.

Sesuai dengan hasil survey dan wawancara dengan para petani di areal persawahan padi sawah dan dinas terkait di Kabupaten Minahasa, para petani masih menggunakan varietas yang tinggi emisi $\mathrm{CH}_{4}$ karena belum adanya informasi mengenai ketersediaan varietas rendah emisi $\mathrm{CH}_{4}$. Hasil penelitian Setyanto (2006) terhadap pengujian beberapa varietas padi sawah irigasi sejak tahun 1995 oleh Balai Penelitian Lingkungan Pertanian Jakenan menunjukkan bahwa varietas Cisadane mengemisi metana paling tinggi jika dibandingkan dengan varietas Ciherang, sedangkan IR36 dan Dodokan paling rendah. Demikian pula hasil penelitian Setyanto et al. (2004), pada hari ke 57 setelah pindah tanam, menunjukkan rata - rata emisi metana paling tinggi pada plot yang ditanam dengan varietas Cisadane dan emisi yang terendah berada pada varietas IR64.

Para petani juga masih menggunakan sistem penggenangan terus-menerus (kontinu), dengan waktu pemberian pupuk dan penggunaan pupuk anorganik yang belum sesuai dengan anjuran pemakaian, termasuk penggunaan bahan organik (jerami) yang langsung dibenamkan tanpa melalui pengolahan lanjutan.

Hasil penelitian Sumardi et al (2007), pemberian air hingga tergenang secara terus - menerus selama periode pertumbuhan padi, jelas merupakan pemborosan air. Hal ini dapat dilihat dari produktivitas air dan efisiensi penggunaan air yang lebih kecil pada kondisi tidak 
tergenang, efisiensi mencapai $19,581 \%$ dan $10,907 \%$ untuk yang digenangi secara terus - menerus.

Pemberian pupuk anorganik ke tanah sawah sesuai dengan hasil penelitian Wihardjaka et al. (2007), mengakibatkan peningkatan fluks gas metana, karena penambahan pupuk anorganik menstimulasi peningkatan emisi gas metana ke atmosfer. Kombinasi bahan organik dengan pupuk anorganik, juga cenderung meningkatkan fluks gas metana. Menurut Wassman et al. (1993), pemberian bahan organik umumnya mempertinggi emisi gas metana dari lahan sawah. Pembenaman jerami ke dalam tanah, nyata meningkatkan laju emisi gas metana dibandingkan pemberian pupuk kandang atau kompos.

Penelitian ini dilakukan untuk mengetahui faktor-faktor yang mempengaruhi produksi emisi gas metana pada budidaya padi sawah di kabupaten Minahasa, dengan melakukan estimasi emisi $\mathrm{CH}_{4}$ menggunakan model perhitungan formula untuk estimasi emisi $\mathrm{CH}_{4}$ pada padi sawah.

\section{METODE}

Penelitian ini menggunakan cara analisis kuantitatif, yaitu model Matematika dengan hasil yang disajikan berupa angka - angka yang kemudian diuraikan atau diinterpretasikan dalam suatu uraian (Moleong 2000).

Model yang dipakai adalah formula untuk estimasi emisi $\mathrm{CH}_{4}$ pada padi sawah (Anonimous, 2006; dan Boer, 2009), dengan memasukkan data primer dan data sekunder sesuai dengan formula sebagai berikut:

$\mathrm{CH}_{4}$ emisi padi $=\mathrm{A} \times \mathrm{CF}_{\text {tanah }} \times S F_{\text {pengairan }} \times E F_{\text {varietas }}$

Yaitu:

$\mathrm{CH}_{4}$ emisi padi $=$ emisi $\mathrm{CH}_{4}$ dari padi sawah ( $\mathrm{Gg} \mathrm{CH}_{4} /$ tahun)

A = luas panen (Ha/tahun) $\begin{array}{ll}\text { CF } & =\text { jenis tanah lahan sawah } \\ \text { SF } & =\text { jenis pengairan } \\ \text { EF } & =\text { jenis varietas padi }\end{array}$

Pengumpulan data primer dilakukan melalui kegiatan survey, pengamatan dan pengukuran langsung di lapangan, sedangkan pengumpulan data sekunder dilakukan pada instansi terkait dengan kegiatan penelitian dan studi literatur yang dapat menunjang data primer. Data primer dan data sekunder yang dikumpulkan meliputi jenis pengairan, jenis tanah, jenis varietas atau bibit padi, data luas panen, dan produksi padi sawah di Kabupaten Minahasa, kegiatan budidaya lainnya seperti pemupukan, panen, pasca panen.

Jenis varietas terbanyak yang ditanam pada lahan sawah di kabupaten Minahasa sejak tahun 1996 - 2010 yaitu Cisadane, tahun 2000 - 2010 Ciherang dan varietas lokal Superwin yang berasal dari benih pokok Cisadane, sehingga dilakukan dua perhitungan dengan menggunakan nilai EFrice (emission factor from rice) untuk varietas yang paling banyak ditanam yaitu varietas Cisadane dan varietas Ciherang.

Berdasarkan penelitian dari IPCC dan Balai Penelitian Lingkungan Pertanian Indonesia, nilai emisi varietas (Efrice) dari varietas Cisadane $=204,60(\mathrm{~kg} \quad \mathrm{CH} 4 / \mathrm{ha} / \mathrm{musim})$ dan varietas Ciherang $=114,80(\mathrm{~kg}$ $\mathrm{CH} 4 /$ ha/musim), nilai faktor koreksi dari jenis tanah (CF atau correction factor) Inceptisol=1,12 dan scaling factor atau SF dari jenis pengairan tergenang atau pengairan terus menerus $=1,00$.

\section{HASIL DAN PEMBAHASAN}

Jenis varietas terbanyak yang ditanam pada lahan sawah di kabupaten Minahasa sejak tahun 1996 - 2010 yaitu Cisadane, tahun 2000 - 2010 Ciherang dan varietas lokal Superwin yang berasal dari benih pokok Cisadane, sehingga dilakukan dua perhitungan dengan 
menggunakan nilai EFrice (emission factor from rice) untuk varietas yang paling banyak ditanam yaitu varietas Cisadane dan varietas Ciherang.

Nilai emisi varietas (EFrice), faktor koreksi dari jenis tanah (CF atau correction factor) dan scaling factor atau SF dari jenis pengairan (tergenang atau pengairan terus menerus, berselang, dan intermitten atau macak - macak), menggunakan nilai berdasarkan penelitian dari IPCC (Intergovernmental Panel on Climate Change) dan penelitian dari Balai Penelitian Lingkungan Pertanian Indonesia.Hasil perhitungan dengan menggunakan formula untuk estimasi emisi $\mathrm{CH}_{4}$, menunjukkan bahwa terjadi peningkatan emisi $\mathrm{CH}_{4}$ pada lahan padi sawah di Kabupaten Minahasa (data tahun 2002 -2010) menurut varietas yang digunakan (Tabel 1 dan 2).

Tabel 1. Total Emisi $\mathrm{CH}_{4}$ di Kabupaten Minahasa pada Tahun 2002 - 2010 untuk Varietas Cisadane

\begin{tabular}{llllll}
\hline Thn & $\begin{array}{l}\text { Luas } \\
\text { Pan } \\
\text { en }\end{array}$ & $\begin{array}{l}\text { Jenis } \\
\text { Tanah }\end{array}$ & $\begin{array}{l}\text { Jenis } \\
\text { Peng } \\
\text { airan }\end{array}$ & $\begin{array}{l}\text { Varie } \\
\text { tas }\end{array}$ & $\begin{array}{l}\text { Emisi } \\
\mathrm{CH}_{4} \\
(\mathrm{~kg}\end{array}$ \\
& & & & & $\begin{array}{l}\mathrm{CH}_{4} / \\
\text { thn })\end{array}$ \\
& & & & & \\
\hline 2002 & 10. & 1,12 & 1,00 & 204,60 & 2.306. \\
& 067 & & & & 873 \\
2003 & 10. & 1,12 & 1,00 & 204,60 & 2.360. \\
& 300 & & & & 265 \\
2004 & 10. & 1,12 & 1,00 & 204,60 & 2.454. \\
& 713 & & & & 905 \\
2005 & 11. & 1,12 & 1,00 & 204,60 & 2.572. \\
& 228 & & & & 918 \\
2006 & 11. & 1,12 & 1,00 & 204,60 & 2.745. \\
& 980 & & & & 241 \\
2007 & 12. & 1,12 & 1,00 & 204,60 & 2.754. \\
& 021 & & & & 636, \\
2008 & 12. & 1,12 & 1,00 & 204,60 & 2.788. \\
& 170 & & & & 779 \\
2009 & 13. & 1,12 & 1,00 & 204,60 & 3.087. \\
& 475 & & & & 823 \\
2010 & 13. & 1,12 & 1,00 & 204,60 & 3.085. \\
& 465 & & & & 531 \\
\hline
\end{tabular}

Data Tabel 1 menunjukkan terjadinya peningkatan total emisi $\mathrm{CH}_{4}$ pada tahun $2002-2010$ di lahan sawah Kabupaten Minahasa dengan menggunakan EF varietas Cisadane. Emisi $\mathrm{CH}_{4}$ tertinggi terjadi pada tahun 2009 dengan luas panen $13.475 \mathrm{Ha}$, yang juga merupakan nilai luas panen tertinggi.

Tabel 2.Total Emisi $\mathrm{CH}_{4}$ di Kabupaten Minahasa pada Tahun 2002 - 2010 untuk Varietas Ciherang

\begin{tabular}{llllll}
\hline Thn & $\begin{array}{l}\text { Luas } \\
\text { Panen }\end{array}$ & $\begin{array}{l}\text { Jenis } \\
\text { Tanah }\end{array}$ & $\begin{array}{l}\text { Jenis } \\
\text { Peng } \\
\text { airan }\end{array}$ & Varietas & $\begin{array}{l}\text { Emisi } \\
\mathrm{CH}_{4} \\
(\mathrm{~kg} \\
\mathrm{CH}_{4} / \\
\text { thn) }\end{array}$ \\
\hline 2002 & 10.067 & 1,12 & 1,00 & 114,80 & 1.294 .374 \\
2003 & 10.300 & 1,12 & 1,00 & 114,80 & 1.324 .332 \\
2004 & 10.713 & 1,12 & 1,00 & 114,80 & 1.377 .434 \\
2005 & 11.228 & 1,12 & 1,00 & 114,80 & 1.443 .651 \\
2006 & 11.980 & 1,12 & 1,00 & 114,80 & 1.540 .340 \\
2007 & 12.021 & 1,12 & 1,00 & 114,80 & 1.545 .612 \\
2008 & 12.170 & 1,12 & 1,00 & 114,80 & 1.564 .769 \\
2009 & 13.475 & 1,12 & 1,00 & 114,80 & 1.732 .561 \\
2010 & 13.465 & 1,12 & 1,00 & 114,80 & 1.731 .275 \\
\hline
\end{tabular}

Data Tabel 2 juga menunjukkan terjadinya peningkatan total emisi $\mathrm{CH}_{4}$ pada tahun 2002 - 2010 di lahan sawah Kabupaten Minahasa dengan menggunakan EF varietas Ciherang. Penggunaan varietas yang berbeda ternyata memberikan pengaruh yang berbeda terhadap jumlah emisi yang dihasilkan. Total emisi dengan menggunakan varietas Cisadane lebih tinggi daripada varietas Ciherang.

Berdasarkan data tersebut, ternyata peningkatan total emisi $\mathrm{CH}_{4}$ dipengaruhi oleh luas panen, jenis varietas, jenis tanah dan jenis pengairan yang sama secara terusmenerus (continous flooded).

Setyanto (2006), menyatakan hasil pengujian beberapa varietas padi sawah irigasi sejak tahun 1995 oleh Balai Penelitian Lingkungan Pertanian Jakenan menunjukkan bahwa varietas Cisadane mengemisi metana paling tinggi jika dibandingkan dengan varietas Ciherang, sedangkan IR36 dan Dodokan paling rendah.

Budidaya padi sawah identik dengan menggenangi lahan pada hampir seluruh periode pertumbuhan padi. Sesuai dengan pengamatan di lapangan, para petani padi sawah di Kabupaten Minahasa, menggenangi lahan mulai dari pembibitan dan hanya mengeringkan lahan ketika padi 
sudah mulai menguning dengan tujuan untuk memudahkan waktu pemanenan.

Sesudah panen, lahan tetap dibiarkan tergenang, sampai proses pengolahan lahan kembali dilakukan. Pola penggenangan terus - menerus seperti ini membutuhkan air dalam jumlah yang besar dan menyediakan lingkungan yang cocok untuk pembentukan $\mathrm{CH}_{4}$, dapat dilihat pada Gambar 1, 2 dan 3.

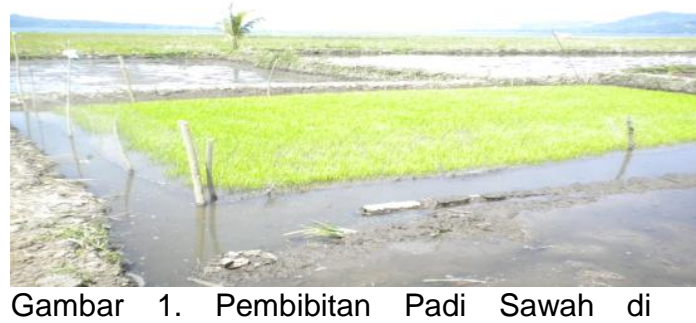

Kecamatan Kakas

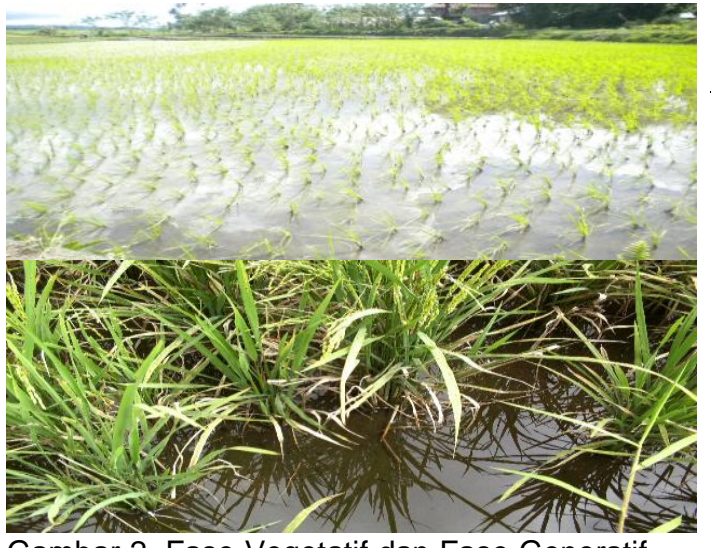

Gambar 2. Fase Vegetatif dan Fase Generatif

Padi Sawah di Kecamatan Tondano Barat

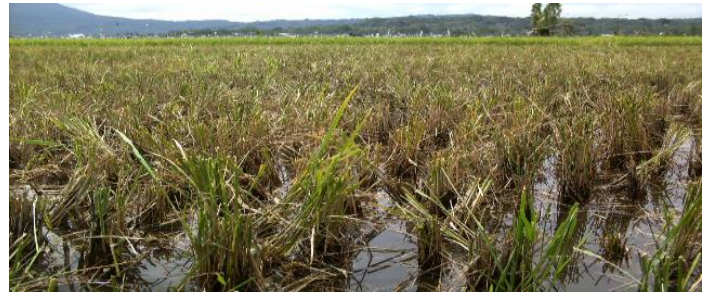

Gambar 3. Pasca Panen Padi Sawah di Kecamatan Tondano Barat

Setyanto dan Kartikawati
(2008) mengadakan penelitian
mengenai sistem pengelolaan
tanaman padi rendah emisi gas
metan, dan dari lima perlakuan, emisi
CH4 tertinggi terdapat pada
perlakuan tergenang, yaitu
PTT(pengelolaan tanaman terpadu)

tergenang $(347+28,4 \mathrm{~kg} / \mathrm{ha})$ dan nonPTT tergenang $(282+36,5 \mathrm{~kg} / \mathrm{ha})$.

Kegiatan budidaya lainnya yang diamati yaitu waktu pemupukan, jenis pupuk dan jumlah pemberian pupuk. Hasil survey dari para petani di kabupaten Minahasa menunjukkan waktu pemberian dan takaran pupuk yang diberikan oleh para petani, belum sesuai dengan anjuran pemberian, pada Tabel 3 dan 4 .

Tabel 3. Jenis dan Waktu Pemberian Pupuk di Lahan Padi Sawah Kabupaten Minahasa

\begin{tabular}{cccc}
\hline \multirow{2}{*}{ Jenis Pupuk } & \multicolumn{3}{c}{ Waktu Pemberian (Hari Setelah } \\
\cline { 2 - 4 } & $30 \mathrm{HST}$ & $\begin{array}{l}50- \\
60 \mathrm{HST}\end{array}$ & $\begin{array}{c}\text { Saat } \\
\text { Buah } \\
\text { Keluar }\end{array}$ \\
\hline $\begin{array}{c}\text { Pupuk } \\
\text { Dasar (Urea } \\
\text { dan }\end{array}$ & $25 \mathrm{~kg} / \mathrm{Ha}$ & $25 \mathrm{~kg} / \mathrm{Ha}$ & $25 \mathrm{~kg} / \mathrm{Ha}$ \\
$\begin{array}{c}\text { KCL/Garam) } \\
\text { Pupuk Daun }\end{array}$ & $50 \mathrm{~kg} / \mathrm{Ha}$ & $50 \mathrm{~kg} / \mathrm{Ha}$ & $50 \mathrm{~kg} / \mathrm{Ha}$ \\
\hline
\end{tabular}

Tabel 4. Waktu Pemberian dan Takaran Pupuk Pada Padi Sawah

\begin{tabular}{|c|c|c|c|c|}
\hline \multirow[t]{2}{*}{ Pupuk } & $\begin{array}{l}\text { Pertum } \\
\text { buhan } \\
\text { Awal }\end{array}$ & $\begin{array}{l}\text { Anakan } \\
\text { Aktif }\end{array}$ & $\begin{array}{l}\text { Pri } \\
\text { mor } \\
\text { dia }\end{array}$ & \multirow[t]{2}{*}{ Matang } \\
\hline & 0-14 HST & $\begin{array}{l}21-28 \\
\text { HST }\end{array}$ & $\begin{array}{l}35- \\
50 \\
\text { HST }\end{array}$ & \\
\hline Nitrogen & $\begin{array}{l}\text { Takaran } \\
\text { Sedang } \\
(50-100 \\
\mathrm{kg} \\
\text { Urea/Ha) }\end{array}$ & $\star \star$ & ** & * \\
\hline $\begin{array}{l}\text { Fosfor } \\
\text { dan } \\
\text { Sulfur }\end{array}$ & $50 \%$ & * & * & * \\
\hline Kalium & $50-100 \%$ & * & * & * \\
\hline
\end{tabular}

Demikian pula dengan pemberian bahan organik berupa sisa-sisa jerami padi yang hanya dibiarkan mengering dan akan dibenamkan pada saat pengolahan tanah untuk musim tanam selanjutnya, tanpa melalui proses pengomposan.

Pemberian pupuk anorganik ke tanah sawah tadah hujan mengakibatkan peningkatan fluks gas metana, karena penambahan pupuk anorganik menstimulasi peningkatan emisi gas metana ke atmosfer. 
Kombinasi bahan organik dengan pupuk anorganik, juga cenderung meningkatkan fluks gas metana, sesuai dengan hasil penelitian Wihardjaka et al. (2007), penambahan pupuk $\mathrm{K}$ dan bahan organik telah menstimulasi peningkatan emisi gas metana.

Menurut Wassman et al. (1993), pemberian bahan organik umumnya mempertinggi emisi gas metana dari lahan sawah. Pembenaman jerami ke dalam tanah, meningkatkan laju emisi gas $\mathrm{CH}_{4}$ secara nyata dibandingkan dengan pemberian pupuk kandang atau kompos.

\section{KESIMPULAN}

Hasil perhitungan jumlah produksi emisi $\mathrm{CH}_{4}$ pada lahan padi sawah di Kabupaten Minahasa, menunjukkan terjadinya kenaikan total emisi $\mathrm{CH}_{4}$ per tahun (data tahun 2002 - 2010).

Faktor - faktor yang mempengaruhi produksi emisi gas metana pada lahan padi sawah di Kabupaten Minahasa yaitu penggunaan jenis varietas Cisadane yang termasuk dalam varietas tinggi emisi $\mathrm{CH}_{4}$, penggenangan sawah menggunakan jenis pengairan terus - menerus, penggunaan pupuk anorganik yang tidak efisien baik dalam jumlah maupun waktu pemberian, dan penggunaan bahan organik (jerami padi) yang dibenamkan setelah panen tanpa melalui proses pengomposan.

\section{DAFTAR PUSTAKA}

Anonimous (2006) 2006 IPCC Guidelines for national greenhouse gas inventories. Switzerland. http://www.ipccnggip.iges.or.jp. Diakses pada 15 April 2010

Anonimous (2007a) Pengurangan emisi gas rumah kaca sektor pertanian. Departemen Pertanian. Jakarta

Anonimous (2007b) Rencana aksi nasional dalam menghadapi perubahan iklim. Kementerian Negara Lingkungan Hidup Republik Indonesia

Boer R (2009) Time series estimates made for Indonesia's GHG inventory included in The SNC 7th workshop on green house gas inventories in Asia. Seoul Republic of Korea

Bouwman AF and Sombroek WG (1990) Inputs to climatic change by soils and agriculture related activities: present status and possible future trends. Dalam: Scharpenseel HW, Schomaker M, Ayoub AT (ed) Soils on a warmer earth. Developments in soil science 20. Elsevier, Amsterdam, pp 15-30

Lindau CW, Patrick WH, Delaune RD, Reddy KR (1990) Rate of accumulation and emission of $\mathrm{N}_{2}$, $\mathrm{N}_{2} \mathrm{O}$, and $\mathrm{CH}_{4}$ from a flooded rice soil. Plant and Soil 129: 269-276

Makarim AK, Suhartatik E (2006) Morfologi dan fisiologi tanaman padi. Balai Besar Penelitian Tanaman Padi

Moleong LJ (2000) Metode penelitian kualitatif. Remaja Rosdakarya. Bandung

Notohadiprawiro, T (1992) Sawah dalam tata guna lahan. Materi ceramah ilmiah Percetakan Lahan Sawah sebagai Salah Satu Alternatif Kebijaksanaan dalam Pengembangan Tata Guna Lahan. UPN. Yogyakarta

Palimbani. 2007. Mengenal pupuk urea. Blog Pustaka Negeri. WordPress.com pusri.wordpress.com/2007/09/22/ mengenal-pupuk-urea/. Diakses pada 4 November 2011

Setyanto P (1997) Lahan sawah dan teknologi pengelolaannya. Mitigasi gas metan dari lahan sawah. Laporan Tahunan Loka Penelitian Tanaman Pangan Jakenan. Jakenan

Setyanto P, Rosenani A.B, Boer R, Fauziah C.I, Khanif M.J. (2004) The effect of rice cultivars on 
methane emission from irrigated rice field. Indonesian Journal of Agriculture Science 5:20-31

Setyanto P (2006) Varietas padi rendah emisi gas rumah kaca. Warta Penelitian dan Pengembangan Pertanian 28

Setyanto P, Abubakar R (2006) Evaluation of methane emission and potential mitigation from flooded rice field. Malaysia

Setyanto P,Kartikawati R (2008) Sistem pengelolaan tanaman padi rendah emisi gas metan. Penelitian Pertanian Tanaman Pangan 27

Steenis V (1981) Flora untuk sekolah di Indonesia. Pradnya Paramita. Jakarta

Sumardi, Kasli M, Kasim A, Syarif, Akhir N. 2007. Respon padi sawah pada teknik budidaya secara aerobik dan pemberian bahan organik. Jurnal Akta Agrosia 10:65-71

Suparyono SA (1994) Padi. Penebar Swadaya. Jakarta

Wagatsuma T, Nakashima T, Tawara K, Watanabe S, Kamio A, Ueki A (1990) Role of plant aerenchyma in wet tolerance and methane emission from plants. Plants Nutrition - Physiology and Applications. pp 455-461

Wassman R, Papen H, Rennenberg $H$ (1993) Methane emission from rice paddies and possible mitigation strategies. Chemosphere 26:201-217

Wihardjaka, S.A, Abdurachman, S 2007. Dampak pemupukan jangka panjang padi sawah tadah hujan terhadap emisi gas metana. Penelitian Pertanian Tanaman Pangan 26. Jakenan 